\title{
Study on Cutting Force, Cutting Temperature and Machining Residual Stress in Precision Turning of Pure Iron with Different Grain Sizes
}

\author{
Yinfei Yang ${ }^{*}$, Lu Jin, Jinpeng Zhu, Jinxing Kong and Liang Li
}

\begin{abstract}
Pure iron is one of the difficult-to-machine materials due to its large chip deformation, adhesion, work-hardening, and built-up edges formation during machining. This leads to a large workpiece deformation and challenge to meet the required technical indicators. Therefore, under varying the grain size of pure iron, the influence of cutting speed, feed, and depth of cut on the cutting force, heat generation, and machining residual stresses were explored in the turning process to improve the machinability without compromising the mechanical properties of the material. The experimental findings have depicted that the influence of grain size on cutting force in the precision turning process is not apparent. However, the cutting temperature and residual stress of machining fine-grain iron were much smaller than the coarse grain at all levels of cutting parameters.
\end{abstract}

Keywords: Pure iron, Grain size, Cutting parameter, Cutting force, Cutting temperature, Residual stress

\section{Introduction}

Pure iron has the characteristics of soft texture, high plasticity and toughness, and excellent electromagnetic properties. It is mostly used in the manufacturing of precision instruments and components in the national defense and military industry. The thin-walled parts made of pure iron are crucial parts of a physical experiment with high machining accuracy. However, due to its poor rigidity and overall size, thin-walled parts deform owing to cutting force, cutting heat, residual stress, which made its accuracy challenging to meet the design requirements [1]. Therefore, it is a crucial and challenging point in the current manufacturing field to explore the mechanism of relevant factors on the machining deformation of thinwalled parts and providing the corresponding theoretical support of processing technology.

In the actual machining process, the above factors lead to the final formation of residual stress. Generally, the mechanical load plays a leading role in the generation

\footnotetext{
*Correspondence: yangyf@nuaa.edu.cn

College of Mechanical and Electrical Engineering, Nanjing University of Aeronautics and Astronautics, Nanjing 210016, China
}

of residual stress at low-speed cutting and low cutting temperature. After the cutting speed increases gradually, and the cutting temperature also rises, the thermal load on the workpiece surface will play a leading role. When the cutting temperature exceeds a specific value, the phase transition of workpiece material will take place. It can, that in the cutting process, the generation of residual stress is extremely complex, which is closely related to the thermal coupling in the material removal process [2-15].

Since the beginning of the last century, numerous experts and scholars have conducted preliminary studies on residual stresses applying many sophisticated testing methods, classified into a) destructive mechanical release measurement b) non-destructive physical measurement [16]. The residual stress of machining is a non-destructive physical method by the X-ray diffraction method and stripping method. Zhang et al. [17] selected the X-ray diffraction method based on a two-dimensional surface survey to measure GH4169 high-temperature alloy and found that two-dimensional surface survey technology could quickly obtain the complete Debye ring of the material, reflecting the crystallographic characteristics of 
Table 1 Chemical composition of electrical pure iron (DT4E)

\begin{tabular}{llllllllll}
\hline Element & $\mathbf{C}$ & $\mathbf{N i}$ & Mn & Si & Cr & S & Cu & P & Al \\
\hline Content $(\leq \%)$ & 0.025 & 0.20 & 0.30 & 0.020 & 0.1 & 0.020 & 0.10 & 0.020 & $0.15-0.50$ \\
\hline
\end{tabular}

the material. Moreover, it shows that the residual stress on the processed surface of the high-temperature alloy studied was uneven, and the microstructure was obvious. Xia et al. [18] measured the residual surface stress of the TP340 steel pipe by using an X-ray diffraction method combined with electrolytic polishing, which provided a reference for the study on reducing the stress corrosion cracking of this kind of steel pipe. Abboud et al. [19] carried out an experimental study on the residual stress in the finishing process of two types of aerospace titanium alloys Ti-64 and Ti-6246, believed that the residual stress is closely related to the cutting parameters. Increasing the material removal rate and reducing the radius of tooltip arc can increase the residual compressive stress on the surface and improve fatigue life. Mohammadpour [14] thought that the residual stress caused by material removal is the result of the multiple cutting. In order to explore the accumulated strain field and temperature field of the effect of residual stress by using multiple-step analysis using finite element software ABAQUS simulation. The authors have analyzed the milling of AISI4140 ultra high strength steel, and the highest temperature had influenced the residual stresses. The accuracy of the model has been proved by experimentation.

The influence of cutting parameters on the cutting force, heat, and machining residual stress has been focused on the turning process. Nevertheless, the influence of grain size on them has not been investigated comprehensively. In order to explore the effects of grain size, two kinds of grain size were selected to analyze their effect on cutting force, heat, and machining residual stress under precision turning of pure iron. The influence of grain size under different feed, cutting speed and depth of cut is analyzed and discussed in Section 3. Some conclusions are given in Section 4.

\section{Experimental Details}

\subsection{Material Preparation}

The pure iron bar (DT4E) material procured from Taiyuan Iron and Steel Company. The chemical composition of the workpiece is provided in Table 1. Its hardness is in the range of $50-80 \mathrm{HB}$, the ultimate tensile strength of $313 \mathrm{MPa}$, and the impact toughness up to $234 \mathrm{~J} / \mathrm{cm}^{2}$.

DT4E pure iron bar of initial grain size 0-grade was prepared, as shown in Figure 1(a). The cold forging process has been used to forge the $\Phi 155 \times 45 \mathrm{~mm}$ pure iron raw materials by $50 \%$ of the compression ratio at $700{ }^{\circ} \mathrm{C}$
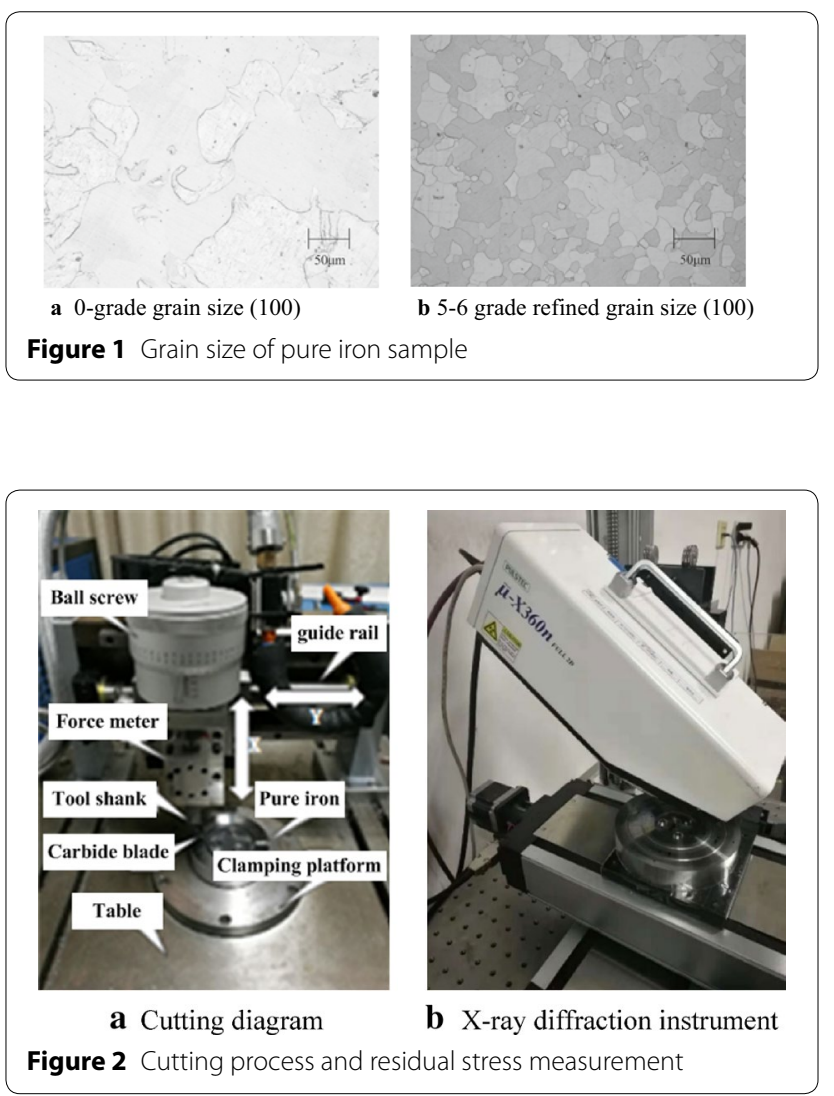

temperature, maintained for two hours, realizing the grain refinement. Then grain size can be controlled in 5 to 6 level, as shown in Figure 1(b).

This section gives a brief description of the experimental setup, machine tool, workpiece material, applied cooling techniques, input and output parameters.

\subsection{Sample Preparation and Selection}

The cutting tool is DCGT11T302 HP sharp carbide blade produced by KENNAMETAL Company. The number of the blade is KC5010, PVD AlTiN coating material. The cutting experiments were conducted on a self-developed vertical lathe. The machine unit has spindle speed from $400-12000 \mathrm{r} / \mathrm{min}$ with a spindle power of $5.7 \mathrm{~kW}$. The workpiece clamping and cutting tools as shown in Figure 2(a). The workpiece was installed the handle for SDJCL2020K11, with installation tool cutting edge angle was $93^{\circ}$, chose to cut the lubricating way of dry cutting 
in processing disc face. According to the requirements of the cutting platform and the clamping, two kinds of grain size of pure black-smith respectively processed into $\Phi 79 \times 20 \mathrm{~mm}$ and $\Phi 123 \times 25 \mathrm{~mm}$ disk with a hole in the middle provided in Figure 2(a).

Cutting force was measured by Kistler 9119AA2 type high-precision three-way force sensor. The cutting temperature was measured by an infrared thermal imager produced by the German InfraTec Company. The model was Image IR 5300, and the temperature range was selected from $150-300{ }^{\circ} \mathrm{C}$. The Phantom series high-speed camera of American VRI Company was used to shoot the precision turning process. The model is VISION V2511, and the highest shooting rate is $1000000 \mathrm{f} / \mathrm{s}$. The focus area was selected as the middle position of the end face to be processed.

Residual stress was measured by X-ray residual stress measurement instrument made in PULSTEC Japanese company, as shown in Figure 2(b). The main composition of pure iron is ferrite materials, so we chose the target of measurement for $\mathrm{Cr}$ in inclination degrees of $35^{\circ}$ and crystal surface of 211 with working voltage and current are respectively $30 \mathrm{kV}$ and $1 \mathrm{~mA}$, its features of transmission line for $\mathrm{Cr}-\mathrm{Ka}$. We can get 125 points by incident only once on residual stress data fitting; the residual stress value is calculated based on the Debye diffraction ring. According to the tool feed direction in the process of turning the end face, the measurement point and direction of residual stress are defined as shown in Figure 3 below.

\subsection{Infrared Thermal Imager Emissivity Check}

Infrared Thermal Imager can convert invisible surface heat radiated by objects above absolute zero into visible images, to generate a thermal image and temperature value [20]. The instrument can not only obtain the thermal field distribution diagram of the tested sample surface but also obtain more accurate temperature data.

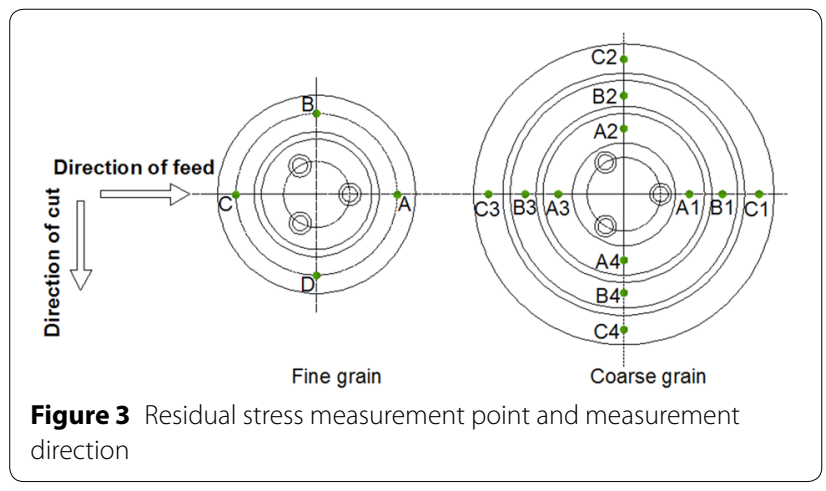

The precise measurement of the data is closely related to the emissivity, solar radiation, ambient temperature, and the corresponding emissivity of the different materials is substantially different. That's why determining the emissivity of the tested surface is of considerable significance through the infrared thermal image temperature measurement technology. The heating furnace was used to heat the coarse and fine grain pure iron workpiece from room temperature to $400{ }^{\circ} \mathrm{C}$, respectively, as shown in Figure 4.

In the heating process, the thermocouple method and infrared thermograph were selected to measure the processed surface temperature of the workpiece simultaneously. The machining parameters of the workpiece were within the range of experimental design parameters. Based on the real-time measurement results of the thermocouple, the radiance is adjusted in the configuration software of the infrared thermometer to keep the temperature consistent. The emissivity of the Infrared Thermal Imager for two kinds of pure iron materials with grain size in different temperature ranges was obtained, as shown in Table 2.

\subsection{Experiment Parameter}

Based on the range of the cutting parameter of the actual finishing pure iron, the test scheme was designed to carry out the single factor cutting test of coarse and fine grain size to measure the cutting force and cutting temperature during the cutting process to analyze the

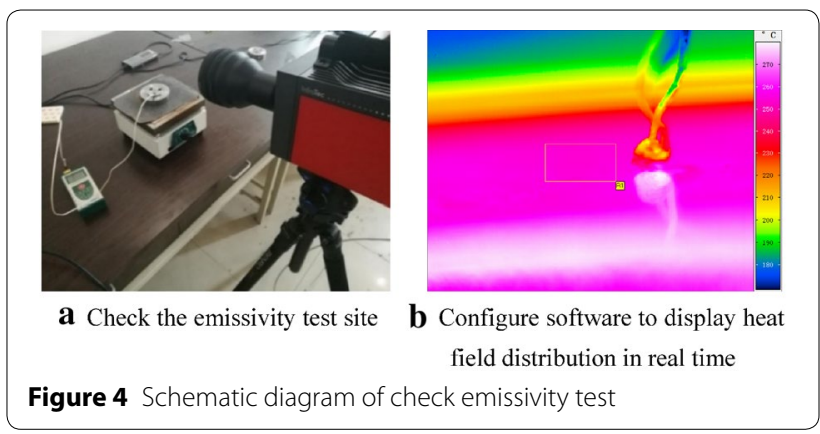

Table 2 Cyclic loading stress parameters

\begin{tabular}{lll}
\hline Temperature range & $\begin{array}{l}\text { Coarse crystal pure } \\
\text { iron }\end{array}$ & $\begin{array}{l}\text { Fine crystal } \\
\text { pure iron }\end{array}$ \\
\hline$T<150^{\circ} \mathrm{C}$ & 0.79 & 0.78 \\
$150^{\circ} \mathrm{C}<T<200^{\circ} \mathrm{C}$ & 0.71 & 0.72 \\
$200^{\circ} \mathrm{C}<T<250^{\circ} \mathrm{C}$ & 0.58 & 0.61 \\
$250^{\circ} \mathrm{C}<T<300^{\circ} \mathrm{C}$ & 0.55 & 0.57 \\
$300^{\circ} \mathrm{C}<T 350^{\circ} \mathrm{C}$ & 0.52 & 0.53 \\
$350^{\circ} \mathrm{C}<T$ & 0.49 & 0.51 \\
\hline
\end{tabular}


influence degree of cutting force and heat-affected by grain size. Cutting parameters are shown in Table 3.

Orthogonal cutting tests of pure iron with three factors and four levels were carried out as shown in Table 4, and groups' results of tests are given in Table 5. The performance measures for this study were the surface residual stresses to analyze the influence of the residual stress on the surface of pure iron at different cutting conditions and grain sizes.

Since the cutting platform used in the test does not have the function of maintaining a constant linear speed with infinitely variable speed, the constant speed when cutting the end face is calculated based on the linear speed designed in the test and the diameter of the middle position of the end face of the disk. The middle diameter of the end face of the fine-grain workpiece is $65 \mathrm{~mm}$, at the mean diameter of the three end faces of the coarse grain workpiece is $55 \mathrm{~mm}$, $83 \mathrm{~mm}$, and $111 \mathrm{~mm}$ from the inside out. In the final collection of cutting force, cutting temperature data, we selected the middle data for analysis to ensure that the corresponding linear speed and the test design was consistent. When measuring the residual stress on the machined surface of the workpiece, since the collimator aperture of the X-ray diffractometer is $2 \mathrm{~mm}$, it can be considered that as long as the measuring point is at the middle position of the end face of the disc, the measured value is the corresponding linear velocity in the test scheme.

\section{Results and Discussion}

\subsection{Influence of Grain Size on Cutting Force and Heat}

Similarly, Hou et al. [21] measured the milling force and surface roughness of the workpiece after milling K4169 superalloy with different grain sizes, and the results showed that smaller grain size was conducive to improving the machinability of the material. Cutting force is one of the underlying physical parameters in the cutting process, which directly affects the generation of cutting heat and then the generation of residual surface stress. Many factors are affecting cutting force, including cutting parameters, tool wear, tool coating, material state of the workpiece and so on. Figure 5 shows the comparison of three-way cutting force and

Table 3 Single-factor cutting test parameters table

\begin{tabular}{lll}
\hline Feed $(\mathbf{m m} / \mathbf{r})$ & Speed of cut $(\mathbf{m} / \mathbf{m i n})$ & Depth of cut $(\mathbf{m m})$ \\
\hline 0.02 & 160 & $0.01,0.03,0.05,0.07$, \\
& & 0.09 \\
$0.01,0.02,0.03,0.04,0.05$ & 120 & 0.04 \\
0.05 & $80,120,160,200,240$ & 0.04 \\
\hline
\end{tabular}

Table 4 Orthogonal test factors and their corresponding levels

\begin{tabular}{llll}
\hline No. & Feed $(\mathbf{m m} / \mathbf{r})$ & $\begin{array}{l}\text { Speed of cut }(\mathrm{m} / \\
\text { min) }\end{array}$ & $\begin{array}{l}\text { Depth } \\
\text { of cut } \\
(\mathbf{m m})\end{array}$ \\
\hline 1 & 0.02 & 80 & 0.01 \\
2 & 0.05 & 120 & 0.04 \\
3 & 0.08 & 160 & 0.07 \\
4 & 0.11 & 200 & 0.10 \\
\hline
\end{tabular}

Table 5 Groups' results of orthogonal tests

\begin{tabular}{llll}
\hline No. & Feed $(\mathbf{m m} / \mathbf{r})$ & $\begin{array}{l}\text { Speed of cut }(\mathbf{m} / \\
\text { min) }\end{array}$ & $\begin{array}{l}\text { Depth } \\
\text { of cut } \\
(\mathbf{m m})\end{array}$ \\
\hline 1 & 0.02 & 80 & 0.01 \\
2 & 0.02 & 120 & 0.04 \\
3 & 0.02 & 160 & 0.07 \\
4 & 0.02 & 200 & 0.10 \\
5 & 0.05 & 80 & 0.04 \\
6 & 0.05 & 120 & 0.01 \\
7 & 0.05 & 160 & 0.10 \\
8 & 0.05 & 200 & 0.07 \\
9 & 0.08 & 80 & 0.07 \\
10 & 0.08 & 120 & 0.10 \\
11 & 0.08 & 160 & 0.01 \\
12 & 0.08 & 200 & 0.04 \\
13 & 0.11 & 80 & 0.10 \\
14 & 0.11 & 120 & 0.07 \\
15 & 0.11 & 160 & 0.04 \\
16 & 0.11 & 200 & 0.01 \\
\hline
\end{tabular}

cutting temperature of two kinds of pure iron materials with grain size in different feed rates when the speed of cut is $120 \mathrm{~m} / \mathrm{min}$, and the depth of cut is $0.04 \mathrm{~mm}$.

It can be seen from Figure 4, the cutting force and cutting temperature of the two kinds of grain increase gradually with the increase of feed, and the value of the main cutting force is the largest, and the value of axial thrust force is the smallest. The figure also shows that the main cutting force increases with the feed the fastest, and the main cutting force of coarse grain is above the fine grain. Within the range of experimental parameters, the three-way cutting forces measured in both coarse and fine grain states is small, and the difference percentage is within $20 \%$. However, as can be seen from Figure 4, the cutting temperature in the fine-grain state is significantly lower than that in the coarse grain state, and the difference percentage is between $6 \%$ and $30 \%$. 


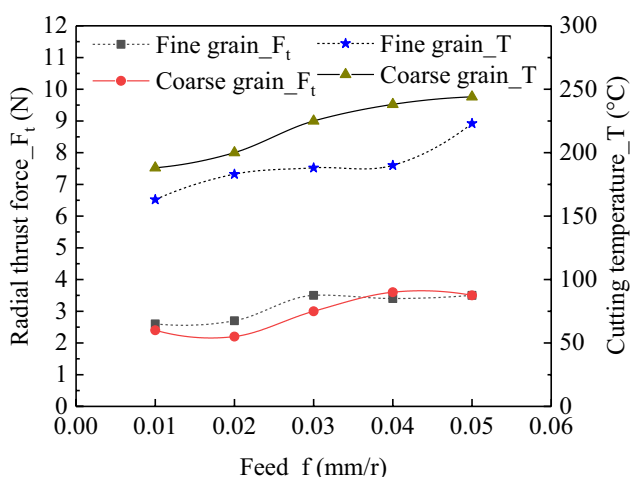

a The radial thrust force and cutting temperature concerning feed rate $(\mathrm{mm} / \mathrm{rev})$

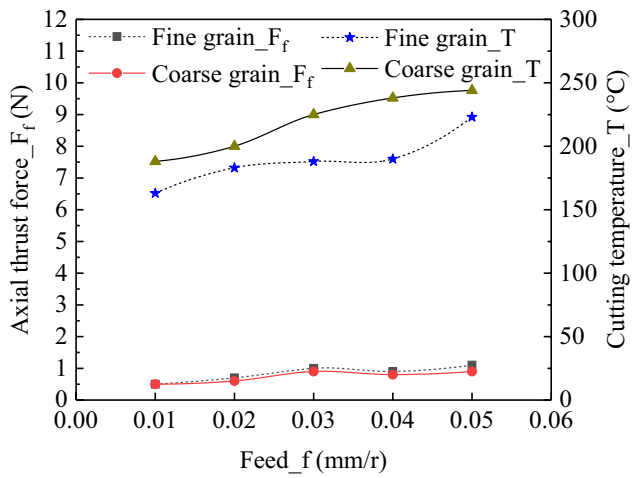

b The axial thrust force and cutting temperature concerning the feed $(\mathrm{mm} / \mathrm{rev})$

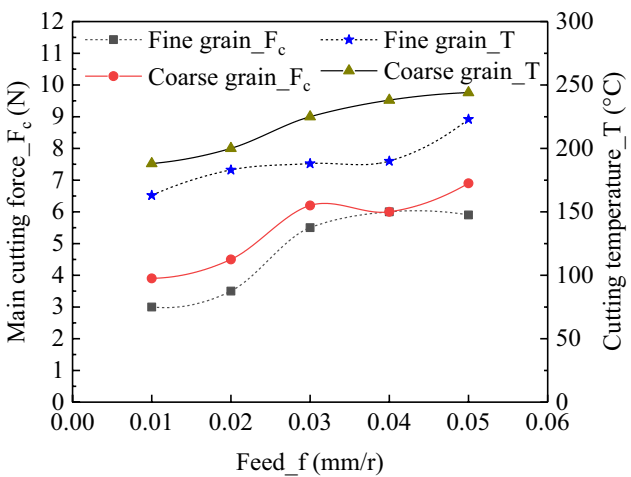

c The main cutting force and cutting temperature concerning the feed $(\mathrm{mm} / \mathrm{rev})$

Figure 5 Comparison of cutting force and temperature at different feed $(\mathrm{mm} / \mathrm{rev})$

Figure 6 shows the comparison of three-way cutting force and cutting temperature of two kinds of grain size in different cutting depths when the feed rate is $0.02 \mathrm{~mm} / \mathrm{r}$ and speed of cut is $160 \mathrm{~m} / \mathrm{min}$. With the increase of depth of cut, the cutting force and cutting

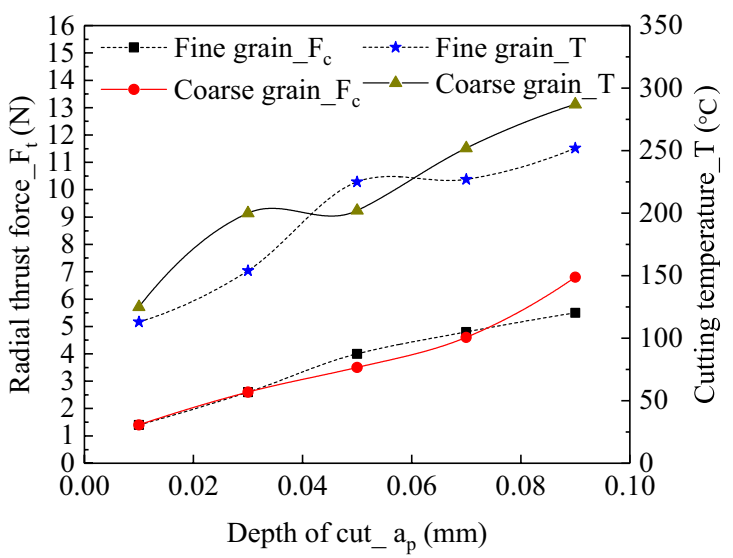

a Radial thrust force and cutting temperature

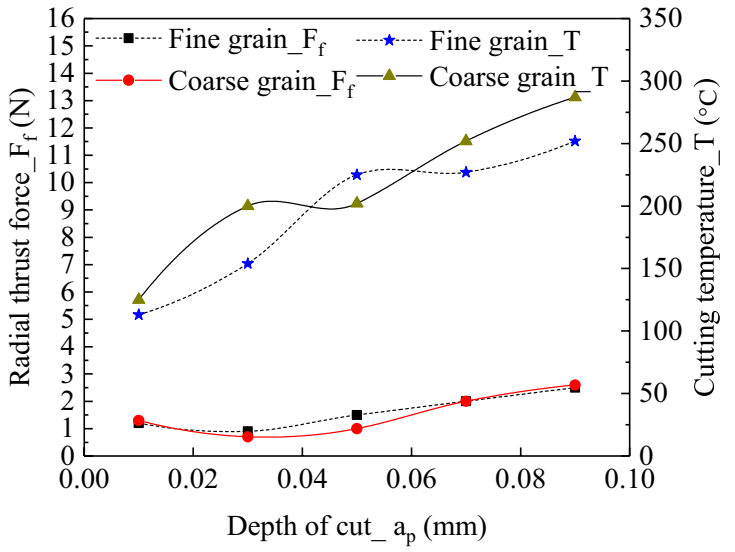

b Axial thrust force and cutting temperature

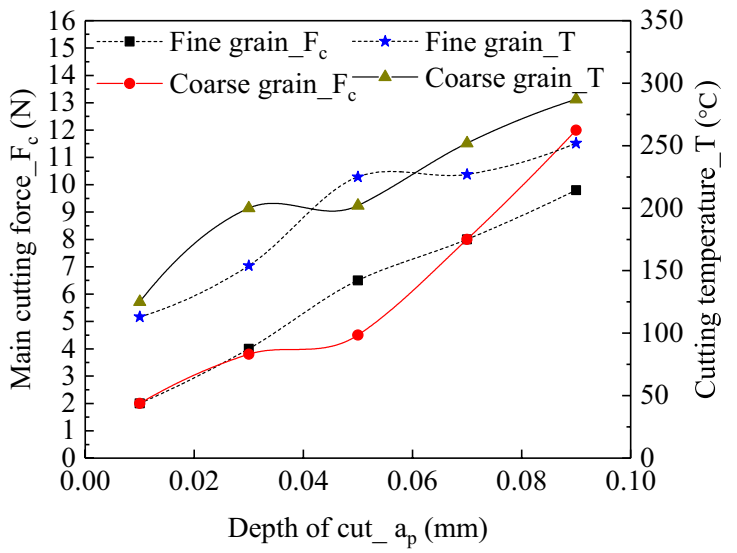

c Main cutting force and cutting temperature

Figure 6 Comparison of cutting force and temperature with different cutting depths

temperature of two kinds of grain increase gradually. Moreover, the value of the main cutting force is the largest, and the value of axial thrust force is the smallest, 
and the main cutting force increases the fastest. Within the range of experimental design parameters, the percentage of three-way cutting force difference between coarse and fine grain materials is within $14 \%$. As can be seen from Figure 5, except for the depth of cut of $0.05 \mathrm{~mm}$ (may measure error), the cutting temperatures in the fine-grain state are significantly lower than those in the coarse grain state, and the difference percentage is between $10 \%$ and $26 \%$.

Figure 7 shows the three-way cutting force and cutting temperature of two-grain states processed at different cutting speeds when the feed rate is $0.05 \mathrm{~mm} / \mathrm{r}$, and the depth of cut is $0.04 \mathrm{~mm}$. With the increase of speed of cut, the cutting force gradually decreases. The figure shows that the main cutting force is the largest and the most apparent reduction, and the axial thrust force value is the minimum, while the main cutting force is significantly higher than fine-grain except for a few groups of coarse crystal pure iron (may measure error). The cutting temperature increases with the increase in cutting speed. The cutting temperature of pure iron in the fine-grain material state is generally smaller than that of pure iron in the coarse grain material state. The numerical deviation is $7.2 \%$ to $21 \%$.

Figure 8 shows the chip outflow process when cutting the pure iron end face at different cutting speeds recorded by the high-speed camera.

Due to the high plasticity and high toughness of pure iron, when the cutting speed is low, the chip deformation is large, and it is easy to cold weld with rake face and bond on the tool surface, and then increases the cutting force, as shown in Figure 8(a). After further increasing the speed of cut, the friction between the bottom of the chip and rake face becomes more intense. The friction heat increases and the flow performance of the chip and rake face increases, which makes the chip slides out along the front surface more smoothly, as shown in Figure 8(b), the retention phenomenon of chip decreases or even disappears, thus reducing the cutting force.

\subsection{Influence of Grain Size on Surface Residual Stress}

A total of 16 groups of tests with three factors and four levels were used in the orthogonal test, aiming to analyze the influence of the residual stress on the machined surface of pure iron material in precision turning with the state of grain material under different cutting parameters and indicate the direction of cut and feed respectively, as shown in Figure 4. The test results are shown in Table 5.

In order to facilitate the comparison, the calculation formula of residual stress difference percentage $w(1)$ and $w(2)$ is defined as follows:

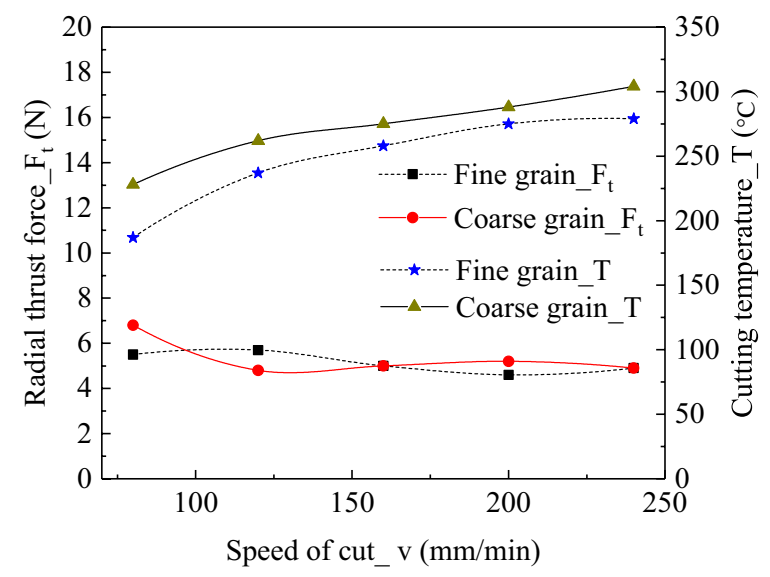

a Radial thrust force and cutting temperature

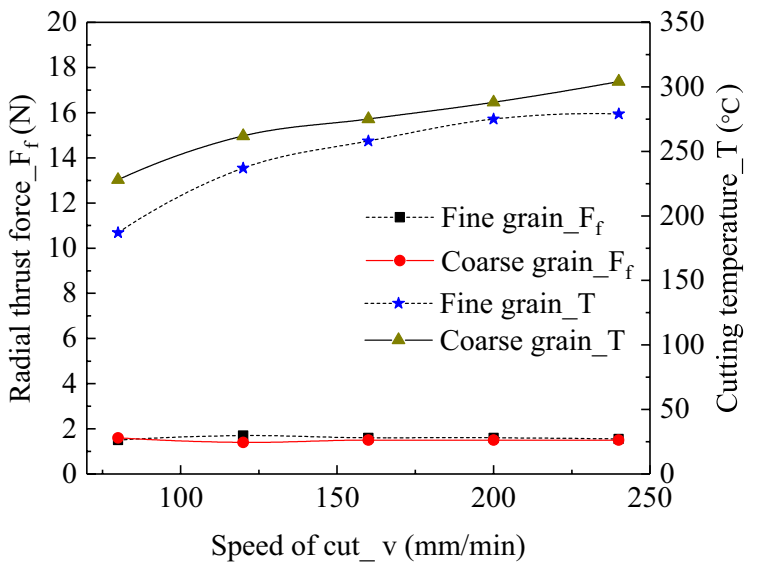

b axial thrust force and cutting temperature

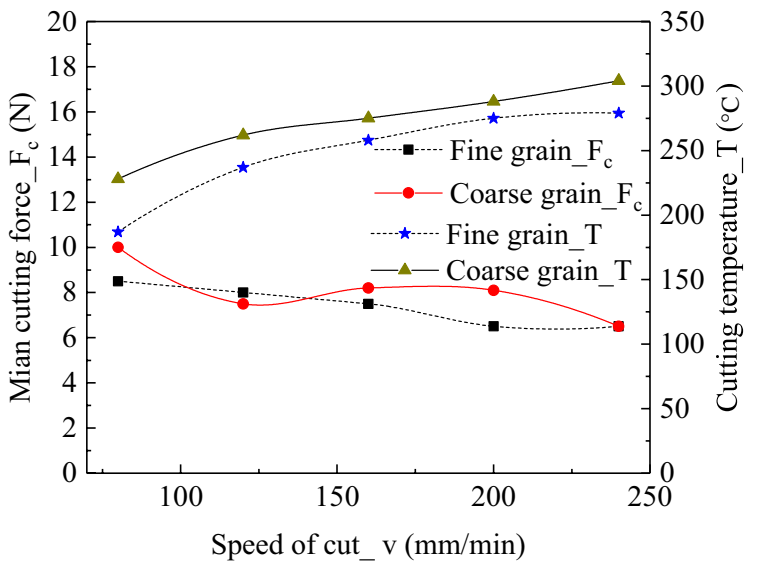

c Main cutting force and cutting temperature

Figure 7 Comparison of cutting force and temperature with different cutting speeds 

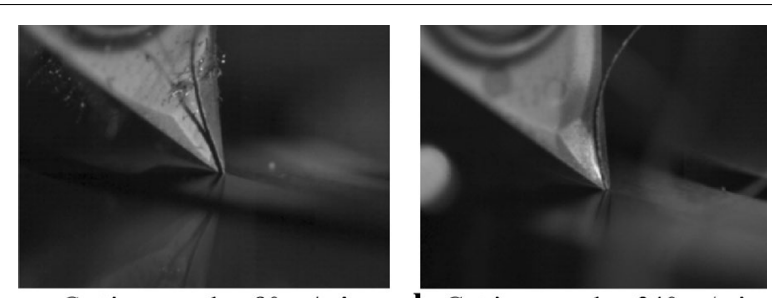

a Cutting speed $v=80 \mathrm{~m} / \mathrm{min} \quad$ b Cutting speed $v=240 \mathrm{~m} / \mathrm{min}$ Figure 8 Chip outflow captured by high-speed camera

$$
\begin{aligned}
& w_{\sigma_{c}}=\frac{\sigma_{c}(\text { Fine grain })-\sigma_{c}(\text { Coarse grain })}{\sigma_{c}(\text { Coarse grain })} \times 100 \%, \\
& w_{\sigma_{f}}=\frac{\sigma_{f}(\text { Fine grain })-\sigma_{f}(\text { Coarse grain })}{\sigma_{f}(\text { Coarse grain })} \times 100 \% .
\end{aligned}
$$

According to the analysis results in Table 6, compared with coarse grain pure iron, the average difference percentage is $-14.66 \%$, and the average difference percentage is $-12.50 \%$, indicating that the residual surface stress of fine grain pure iron is less than that of coarse grain pure iron.

The average main effect diagram reflects how each factor affects response characteristics. When different levels of factors have different effects on response characteristics, there is a main effect [22]. For different levels corresponding to the surface, residual stress should calculate the average, and then draw a graph line. By comparing the slope, the difference of the relative influence of cutting parameters on the two kinds of pure iron grain size can be analyzed.

As shown in Figure 9, on the main cutting force direction, surface residual stress of two kinds of state grain is most affected by the feed. The depth of cut has greater effect on residual surface stress of coarse grain than the fine grain. With cutting speed and cutting depth increases, the residual surface stress of fine-grain appears certain fluctuation, but do not increase or decrease dramatically. In the direction of feed, the feed has the most significant influence on the residual surface stress of twograin size. When the depth of cut increases, the residual stress fluctuates to different degrees, and cutting parameters have a smaller effect on surface residual of fine-grain than coarse grain.

\section{Conclusions}

This work presents an endeavor to obtain better machinability of pure iron. This experimental study has put forward a clear comparison of two-grain sizes, such as a level 0 and 5-6 levels of the two kinds of grain size. Essential output responses, namely, cutting force, temperature, and machining residual stress were evaluated on the precision turning of pure iron. The following conclusions have been derived based on obtained results.

(1) The cutting force results show that the effect of cutting parameter on the main cutting force is the greatest, and on the base of the influence of grain size is also the greatest. The cutting force of fine grain is less $2 \mathrm{~N}$ than coarse grain, but in general,

\begin{tabular}{|c|c|c|c|c|c|c|}
\hline Number & $\begin{array}{l}\text { Coarse grain } \\
\sigma_{c}(\mathrm{MPa})\end{array}$ & $\begin{array}{l}\text { Fine grain } \\
\sigma_{c}(\mathrm{MPa})\end{array}$ & $w_{\sigma_{c}} \%$ & $\begin{array}{l}\text { Coarse grain } \\
\sigma_{f}(\mathrm{MPa})\end{array}$ & $\begin{array}{l}\text { Fine grain } \\
\sigma_{f}(\mathrm{MPa})\end{array}$ & $w_{\sigma_{f}} \%$ \\
\hline 1 & 214 & 219 & $\downarrow-73.89$ & -45 & -12 & $\uparrow 2.22$ \\
\hline 2 & 249 & 270 & $\uparrow 18.00$ & 75 & 89 & $\uparrow 8.75$ \\
\hline 3 & 309 & 312 & $\uparrow 16.54$ & 127 & 148 & $\uparrow 0.81$ \\
\hline 4 & 381 & 234 & $\downarrow-21.30$ & 100 & 79 & $\downarrow-38.58$ \\
\hline 5 & 356 & 359 & $\downarrow-2.80$ & 143 & 139 & $\uparrow 0.84$ \\
\hline 6 & 403 & 314 & $\uparrow 18.75$ & 224 & 266 & $\downarrow-22.19$ \\
\hline 7 & 438 & 425 & $\uparrow 37.11$ & 113 & 154 & $\downarrow-3.08$ \\
\hline 8 & 439 & 365 & $\downarrow-36.02$ & 220 & 141 & $\downarrow-16.91$ \\
\hline 9 & 409 & 321 & $\downarrow-30.18$ & 164 & 115 & $\downarrow-21.56$ \\
\hline 10 & 461 & 386 & $\uparrow 26.39$ & 144 & 182 & $\downarrow-16.37$ \\
\hline 11 & 401 & 396 & $\downarrow-57.41$ & 270 & 115 & $\downarrow-1.43$ \\
\hline 12 & 396 & 431 & $\uparrow 8.23$ & 216 & 234 & $\uparrow 8.71$ \\
\hline 13 & 394 & 432 & $\downarrow-13.25$ & 145 & 126 & $\uparrow 9.72$ \\
\hline 14 & 414 & 413 & $\uparrow 36.44$ & 159 & 216 & $\downarrow-0.18$ \\
\hline 15 & 428 & 430 & $\uparrow 23.61$ & 229 & 283 & $\uparrow 0.41$ \\
\hline 16 & 384 & 439 & $\uparrow 9.78$ & 276 & 303 & $\uparrow 14.26$ \\
\hline
\end{tabular}

Table 6 Measurement results of residual stresses on the surface of coarse and fine grain pure iron 


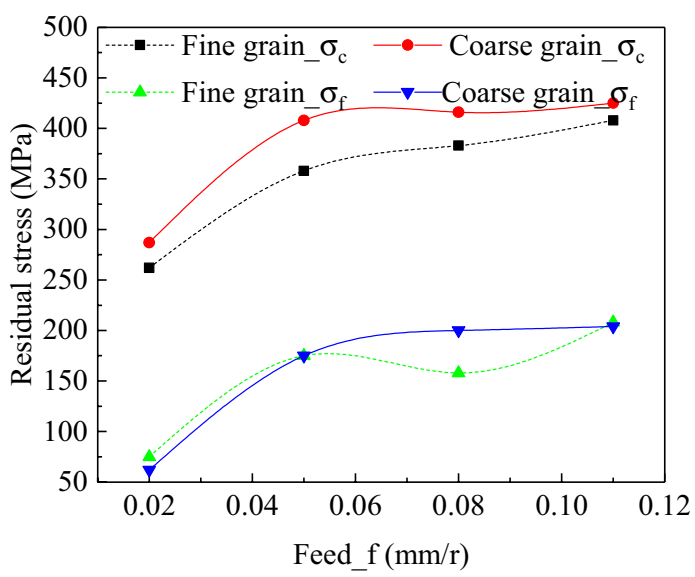

a Residual stress reflect to feed $(\mathrm{mm} / \mathrm{rev})$

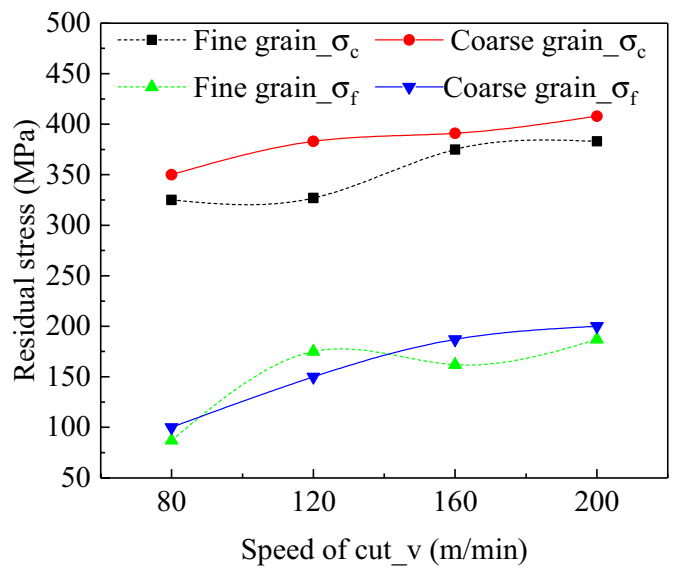

b Residual stress reflect to the speed of cut $(\mathrm{m} / \mathrm{min})$

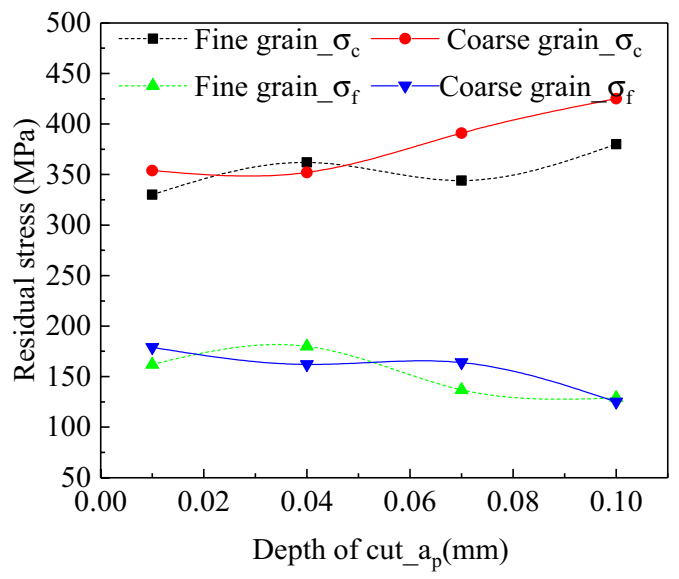

c Residual stress reflects on the depth of cut $\mathrm{a}_{\mathrm{p}}(\mathrm{mm})$

Figure 9 Mean main effect diagram of residual stresses on the surface of coarse and fine grain pure iron the influence of cutting force of grain size in the finish turning process is not obvious.

(2) The cutting temperature results show that the cutting temperature of fine-grain was smaller $50{ }^{\circ} \mathrm{C}$ than the coarse grain. This indicates that fine grain of pure iron in finishing can get smaller the cutting temperature.

(3) Surface residual stress results show that every cutting parameter of fine-grain overall less surface residual stress than coarse grain. Under the same parameters after processing, the residual surface stress of fine grain of pure iron is less than the coarse grain, which obtains better cutting machinability.

\section{Acknowledgements}

The authors sincerely thank to Ning He and Muhammad Jamil of College of Mechanical and Electrical Engineering, Nanjing University of Aeronautics and Astronautics for their critical discussion and reading during manuscript preparation.

\section{Authors' Information}

Yinfei Yang, born in 1982, is currently the associate professor at College of Mechanical and Electrical Engineering, Nanjing University of Aeronautics and Astronautics, China.

Lu Jin, born in 1994, is currently a master candidate at College of Mechanical and Electrical Engineering, Nanjing University of Aeronautics and Astronautics, China.

Jinpeng Zhu, born in 1993, is a master candidate at College of Mechanical and Electrical Engineering, Nanjing University of Aeronautics and Astronautics, China.

Jinxing Kong, born in 1987, is doctoral candidate at College of Mechanical and Electrical Engineering, Nanjing University of Aeronautics and Astronautics, China.

Liang Li, born in 1959, is currently a professor at College of Mechanical and Electrical Engineering, Nanjing University of Aeronautics and Astronautics, China.

\section{Authors' Contributions}

$\sqcup J$ and JZ were in charge of the whole trial; $L J$ wrote the manuscript; YY, LL and JK assisted with sampling and laboratory analyses. All authors read and approved the final manuscript.

\section{Funding}

Supported by National Defense Foundation Pre-Research Science Challenge Project (Grant No. JCKY2016212A506-0107) and Development Funds of China Academy of Engineering Physics (Grant No. 2015B0203029).

\section{Competing Interests}

The authors declare no competing financial interests.

Received: 19 July 2019 Revised: 16 June 2020 Accepted: 17 July 2020 Published online: 29 July 2020

\section{References}

[1] H Sasahara. The effect on fatigue life of residual stress and surface hardness resulting from different cutting conditions of $0.45 \% \mathrm{C}$ steel. International Journal of Machine Tools \& Manufacture, 2005, 45(2): 131-136.

[2] J D Thiele, S N Melkote. Effect of cutting edge geometry and workpiece hardness on surface generation in the finish hard turning of AISI 52100 steel. Journal of Materials Processing Technology, 1999, 94(2): 216-226. 
[3] E Brinksmeier, J T Cammett, W König, et al. Residual stresses-measurement and causes in machining processes. CIRP Annals-Manufacturing Technology, 1982, 31(2): 491-510.

[4] K H Fuh, C F Wu. A residual-stress model for the milling of aluminum alloy. Journal of Materials Processing Technology, 1995, 51(1-4): 87-105.

[5] $\mathrm{M} \mathrm{H}$ El-Axir. A method of modeling residual stress distribution in turning for different materials. International Journal of Machine Tools \& Manufacture, 2002, 42(9):1055-1063.

[6] B R Sridhar, G Devananda, K Ramachandra, et al. Effect of machining parameters and heat treatment on the residual stress distribution in titanium alloy IMI-834. Journal of Materials Processing Technology, 2003, 139(1-3): 628-634.

[7] STorbaty, A Moisan, J L Lebrun, et al. Evolution of residual stress during turning and cylindrical grinding of a carbon steel. CIRP Annals - Manufacturing Technology, 1982, 31(1): 441-445.

[8] ZTTang, Z Q Liu, Y Wan, et al. Study on residual stresses in milling aluminium alloy 7050-T7451. In: XTYan, C Jiang, B Eynard, eds. Advanced design and manufacture to gain a competitive edge, Springer, London, 2008: 169-178.

[9] S Jeelani, S Biswas, R Natarajan. Effect of cutting speed and tool rake angle on residual stress distribution in machining 2024-T351 aluminium alloy-unlubricated conditions. Journal of Materials Science, 1986, 21 (8): 2705-2710

[10] E Capello. Residual stresses in turning: Part I: Influence of process parameters. Journal of Materials Processing Technology, 2005, 160(2): 221-228.

[11] B Denkena, L D Leon. Milling induced residual stresses in structural parts out of forged aluminium alloys. International Journal of Machining and Machinability of Materials, 2008, 4(4): 335.

[12] B Coto, V G Navas, O Gonzalo, et al. Influences of turning parameters in surface residual stresses in AISI 4340 steel. International Journal of Advanced Manufacturing Technology, 2011, 53(9-12): 911-919.
[13] V G Navas, O Gonzalo, I Bengoetxea. Effect of cutting parameters in the surface residual stresses generated by turning in AISI 4340 steel. International Journal of Machine Tools \& Manufacture, 2012, 61: 48-57.

[14] M Mohammadpour, M R Razfar, R J Saffar. Numerical investigating the effect of machining parameters on residual stresses in orthogonal cutting. Simulation Modelling Practice and Theory, 2010, 18(3): 378-389.

[15] ZX Qi, B Li, L S Xiong. The formation mechanism and the influence factor of residual stress in machining. Frontiers of Mechanical Engineering, 2014, 9(3): 265-269.

[16] W Rae, Z Lomas, M Jackson, et al. Measurements of residual stress and microstructural evolution in electron beam welded Ti-6Al-4V using multiple techniques. Materials Characterization, 2017, 132: 10-19.

[17] Y E Zhang. Residual stress analysis of high temperature alloy GH4169 by two-dimensional detector method. Surface Technology, 2016.

[18] Z Q Xia, W S Gu, S G Zhu. Surface residual stress of TP304 stainless steel thin wall tube. Physical Testing \& Chemical Analysis, 2010.

[19] E Abboud, H Attia, B Shi, et al. Residual stresses and surface integrity of Tialloys during finish turning-guidelines for compressive residual stresses. Procedia CIRP, 2016, 45: 55-58.

[20] Y Y Wu, T G Luo, X L Yang, et al. Calculation of object surface emissivity based on measuring temperature principle of thermal imager. Helicopter Technique, 2011.

[21] J Z Hou, Z L Zhao, G M Yan, et al. The changing of machinability of superalloys after grain refinement. Metallic Functional Materials, 2007.

[22] N Hong, J Hou, Z H Li. MINITAB statistical analysis course. Beijing: Electronic Industry Press, 2007.

\section{Submit your manuscript to a SpringerOpen ${ }^{\odot}$ journal and benefit from:}

- Convenient online submission

- Rigorous peer review

- Open access: articles freely available online

- High visibility within the field

- Retaining the copyright to your article

Submit your next manuscript at $\boldsymbol{\nabla}$ springeropen.com 